\title{
The Editor-in-Chief's Foreword to the Special Issue of the Journal Issledovanie Zemli iz Kosmosa
}

DOI: $10.1134 / \mathrm{S} 0001433814090059$

One of the most advanced and rapidly developing trends in the Earth remote sensing (ERS) is the use of innovative hyperspectral methods and technologies. At present, hyperspectral aerospace images are used increasingly widely in the interests of environmental monitoring to study and rationally use natural resources, as well as to prevent and eliminate the consequences of natural calamities and anthropogenic accidents, as well as in meteorology, climatology, forestry, agriculture, transportation, basic earth sciences, and so on.

The main distinguishing feature of hyperspectral information is the possibility to analyze simultaneously the spatial and spectral characteristics of objects, processes, and phenomena under observation. A data "hypercube" is used; it consists of lines and columns that form a matrix of the spatial distribution of luminances together with the third coordinate, which is the wavelength of recorded electromagnetic radiation.

The wide application of hyperspectral methods and technologies in aerospace monitoring is currently hindered by the small number of satellites and aerial carriers equipped with hyperspectrometers with the required characteristics, as well as by difficulties related to the processing and interpretation of the large flows of information formed by these tools. In this context, the effective use of data received during aerospace monitoring requires a wider application of stateof-the-art hyperspectral sensors installed on space and aerial carriers, as well as the development and applica- tion of efficient methods, technologies, and highly productive software and hardware to process the large flows of hyperspectral information.

The RAS journal Issledovanie Zemli iz Kosmosa has dedicated two special issues to these problems. The topicality of such special issues is also determined by the fact that the Resurs-P spacecraft with hyperspectral equipment was successfully launched in 2013.

The articles in these special issues are based on the materials of the papers presented by authors at scientific conferences, including the science and technology conference "Hyperspectral Instruments and Technologies," which was hosted by the OJSC Krasnogorskii zavod im. S.A. Zvereva (OAO KMZ) in January 2013. The main task posed by the organizers of this conference was to rally the representatives of scientific and industrial organizations in one place so that they could cover and discuss the outlooks for the development and implementation of hyperspectral methods, technologies, and tools, as well as to exchange new ideas and knowledge in a constructive dialog and to establish mutually beneficial links.

This issue of the journal is the first of the two planned issues. It covers a number of topical problems concerning the development and use of hyperspectral methods and technologies for remote sensing of the Earth. 